\title{
Os lugares da psicologia na educação médica
}

This paper discusses the place that psychology occupies within three medical courses in the city of São Paulo, Brazil. The theoretical basis was the discursive practices approach within the constructionist framework of social psychology. To reach the objective, we conducted interviews with teachers responsible for the discipline of medical psychology within these three courses. Analysis of the material allowed us to observe that psychological theories are not seen as a priority within the training, but that they are learned through interpersonal relationships among the students and between students and teachers. We conclude that the discipline of medical psychology is the space for learning and reflecting on the relationship between (future) doctors and their patients as well as being a place for dealing with and caring for students' various experiences during the undergraduate course.

Key words: Medical education. Medical psychology. Social psychology. Discursive practices. Social constructionism.
Este artigo problematiza os lugares que a psicologia ocupa em três cursos de medicina da cidade de São Paulo-SP. Tem como base teórica a abordagem das práticas discursivas no referencial construcionista da psicologia social. Para alcance do objetivo fizemos entrevistas com docentes responsáveis pela disciplina psicologia médica dos referidas cursos. A análise do material nos permitiu constatar que não se dá prioridade na formação às teorias psicológicas, mas que elas são aprendidas durante as relações interpessoais ocorridas entre os/as alunos/as e destes/as com os/as professores/as. Concluímos que a disciplina psicologia médica é o espaço de aprendizado e reflexão a respeito da relação entre o/a (futuro/a) médico/a e seus/as pacientes, além de ser um lugar para se lidar e cuidar das diversas experiências suscitadas nos/as alunos/as durante o curso de graduação.

Palavras-chave: Educação médica. Psicologia médica. Psicologia social. Práticas discursivas. Construcionismo social.
${ }^{1}$ Psicólogo. Curso de Medicina, Universidade Federal do Tocantins. 109 Norte Av., NS 15, ALCNO14, Palmas, TO, Brasil. 77.001-090 sergioaragaki@uft.edu.br 2 Psicóloga. Programa de Estudos Pós-Graduados em Psicologia Social, Pontifícia Universidade Católica de São Paulo. 


\section{Introdução}

Partimos do entendimento de que, durante a graduação em medicina, os/as alunos/as ressignificam os conteúdos aprendidos em seus processos de socialização à luz do que é considerado assunto e campo de atuação legítimos de sua futura profissão. Assim, o conhecimento médico se caracteriza como uma área específica que inclui determinados conceitos e ações e exclui outros, considerados nãopertinentes à medicina.

De acordo com Matta e Camargo Jr. (2007), Pessotti (1996) e Balint (1975), a biomedicina é o paradigma predominante da medicina ocidental moderna. Foucault (1979) afirma que ela surgiu no século XIX, da junção entre a semiologia clínica, a anatomia patológica e a microbiologia. A biomedicina busca a cura de doenças dos seres humanos, sendo estes entendidos como um conjunto de células, órgãos e funções fisiológicas. Nesta perspectiva, o médico é preparado "para tratar um paciente que não é um homem, é um corpo humano" (Pessotti, 1996, p.443).

Entretanto, em sua prática, o/a profissional se defronta com uma pessoa que sofre não só por motivos orgânicos, mas também emocionais e sociais, o que impõe à medicina "uma volta ao estudo do homem [...] uma ação do médico sobre o homem integral e menos sobre a máquina orgânica" (Pessotti, 1996, p.443).

De acordo com Caprara e Franco (1999), a preocupação em recuperar questões que envolviam o relacionamento entre médico/a e paciente se fazia presente desde a segunda metade do século XX, com os estudos de Schneider (1994), Jaspers (1991) e Boltanski (1979), dentre outros.

Matta e Camargo Jr. (2007), por sua vez, afirmam que, com base no trabalho de Balint (1975), no Reino Unido, e de Perestrello (1974), no Brasil, nasceu "um campo ainda difuso, ora denominado medicina psicossomática, ora psicologia médica" (p.134).

Assim, como decorrência das contribuições dos autores acima expostos, por meio da disciplina psicologia médica (e correlatas), espera-se que se tenha, ao final da formação médica, "um profissional com consciência política, cidadania e ética, que seja promotor da transformação da sociedade, que alie competência a uma visão humanitária, vendo o paciente através e além dos sintomas" (Cruz, 2004, p.53). Nessa(s) disciplina(s) ocorrem aproximações com aquilo que é comumente designado como "psicológico", uma vez que há uma apropriação de conhecimentos e que se desenvolve um linguajar para designar e tratar as questões psicológicas do/a paciente.

Percebemos que há diferentes maneiras de interpretar e explicar os aspectos psicológicos do adoecimento na prática médica. Isto é, os/as médicos/as identificam e nomeiam vários fenômenos como "psicológicos", atribuindo-lhes sentidos e usos diversos.

Diante disso, nossa proposta é entender os lugares que a psicologia ocupa na formação médica, em três cursos de medicina situados na cidade de São Paulo-SP. Este estudo foi feito no enquadre do construcionismo em psicologia social, tomando por base o estudo das práticas discursivas de docentes coordenadores da disciplina psicologia médica.

\section{Abordagem teórica}

Este artigo tem como base teórica as práticas discursivas na perspectiva do construcionismo social. Nesta abordagem a linguagem adquire função central no conhecimento do mundo, pois as trocas linguísticas permitem que se operem os processos de objetivação necessários à construção da realidade. Essas trocas são consideradas produtos de um determinado contexto histórico-cultural e se dão por meio de um processo de negociação de sentidos entre as pessoas envolvidas (Gergen, 1985), havendo a escolha pelos/as participantes do(s) sentido(s) que mais se adaptam àquilo que está sendo argumentado, defendido ou refutado.

Se todo conhecimento é construído na interação entre seres humanos, o embasamento da prática médica em uma visão humanista também deve ser assim considerado. Decorre disto a relevância de atentarmos para as práticas discursivas que atravessam a formação médica.

Práticas discursivas são linguagem em ação, ou seja, "as maneiras a partir das quais as pessoas produzem sentidos e se posicionam em relações sociais cotidianas" (Spink, Medrado, 1999, p.45). Para 
compreendê-las é necessário levarmos em conta a dialogicidade dos enunciados (Bakhtin, 1929/1995) e os repertórios interpretativos (Potter et al., 1990; Wetherell, Potter, 1988).

Enunciado é o conjunto de palavras e sentenças articuladas em ações situadas que expressam um determinado ponto de vista (voz), explicitando: a visão de mundo, a perspectiva, o horizonte conceitual e as intenções de quem fala. Uma voz não existe isoladamente, mas a sua compreensão se dá por meio do confronto de vozes. Dessa forma, os enunciados de uma pessoa estão sempre em contato ou são endereçados a uma outra pessoa, e estes se interanimam mutuamente (Bakhtin, 1929/1995).

O entendimento de um enunciado implica reconhecer a processualidade das práticas discursivas, já que cada enunciado interage com enunciados anteriores, assim como com os que o seguirão (contraargumentação antecipada). Os diálogos podem se dar internamente, com pessoas presentes ou distanciadas no tempo ou no espaço. De acordo com Wertsch (1991), podem também ocorrer com um "outro" não concretizado, indefinido.

Para Bakhtin (1929/1995), “o conceito de autoria única, isolada não existe. Um aspecto essencial de seu conceito de dialogicidade é que a autoria múltipla é um fato necessário em todos os textos, escritos ou orais" (Wertsch, 1991, p.49). Para entendermos um enunciado, temos de considerá-lo no contexto em que foi produzido. Em suma, a compreensão de todo e qualquer fenômeno é sempre dialógica.

De acordo com Davies e Harré (1990), a dialogicidade caracteriza as práticas discursivas, e é por meio dela que as pessoas produzem realidades psicológicas e sociais de forma ativa. Porém, para o entendimento das relações entre pessoas, também é fundamental considerarmos os repertórios interpretativos (Potter et al., 1990; Wetherell, Potter, 1988), ou seja, os dispositivos linguísticos utilizados para construirmos as diferentes versões dos fenômenos que nos cercam.

Os repertórios nos permitem o acesso à polissemia presente nos discursos, isto é, os diferentes sentidos de uma mesma palavra, numa época determinada. Para além de regularidades e consensos, eles tornam possível acompanharmos a linha de argumentação utilizada para apresentar ou defender uma idéia que, em vez de se mostrar coerente, comporta também contradições e um processo contínuo de negociação de sentidos.

Com base nessas considerações teóricas, esclarecemos que, para o alcance de nosso objetivo, fizemos entrevistas que foram tratadas como processos dialógicos e cujos conteúdos foram tomados em contexto. Desse modo, reativaram-se repertórios e vozes que circulam no âmbito da prática médica, assim como no senso comum de nossas vidas.

\section{Objetivo}

Explicitar e problematizar os lugares que a psicologia ocupa na formação médica, de acordo com profissionais que acumulam a dupla função de docentes e coordenadores da disciplina psicologia médica, em três cursos de medicina de São Paulo-SP.

\section{Metodologia}

Para alcance do objetivo, foram entrevistados docentes coordenadores/as da disciplina psicologia médica de três cursos de medicina da cidade de São Paulo. Tais cursos foram escolhidos por causa de sua tradição na educação médica e na prestação de serviços de saúde à população de São Paulo e do país.

Dessa forma, colaboraram, na pesquisa, três pessoas, que participaram de uma entrevista individual semiestruturada, informadas previamente que foram escolhidas em virtude da função que exercem na formação médica. Elucidamos que todos/as são médicos/as psiquiatras e dialogam com a psicanálise. Dentre eles/as, um/a se identifica, também, com a psicologia jungiana.

As entrevistas ocorreram no início de 2000 , em local, data e horário por eles/as sugeridos. Tiveram duração média de quarenta minutos, tendo sido solicitada autorização para gravação em áudio.

Para assegurar os direitos dos/as entrevistados/as, foram respeitadas as diretrizes e normas da resolução 196/96 do Conselho Nacional de Saúde (Brasil, 1996) e do código de ética profissional dos 
psicólogos (Conselho Federal de Psicologia, 1987) ${ }^{3}$. Além disso, tomamos cuidado para garantir o diálogo, assim como o direito de não-resposta, minimizando relações abusivas de poder entre entrevistador e entrevistados/as. No início de cada entrevista solicitamos a assinatura de consentimento informado.

As entrevistas focalizaram a formação do/a médico/a, de forma ampla, centrando, mais especificamente, em como e em que momento aquilo que é considerado "psicológico" é tratado durante o curso. As perguntas norteadoras da entrevista foram:

- Que aspectos considera importante na formação médica?

- Quando se insere e como é referida a questão do "psicológico" na formação médica?

- Qual a função da disciplina psicologia médica nessa formação?

- Que conteúdos a disciplina ministrada aborda?

- Que conteúdos deveria abordar?

- Como considera a formação que o/a médico/a tem a respeito do "psicológico" na faculdade em que ministra aula de psicologia médica?

- Como definiria o "psicológico" ou algo que é "psicológico"?

- Cite um livro ou texto fundamental para a formação médica, a respeito do "psicológico".

Os discursos foram tomados como posicionamentos profissionais, uma vez que os/as coordenadores/as têm pouca flexibilidade para alterar o conteúdo da disciplina, pois devem observar as normas ditadas pelo Ministério da Educação (Brasil, 2001a, 2001b) e a ementa da disciplina, elaborada e aprovada previamente pela instituição.

Para manter o anonimato, as pessoas serão referidas como: C1, C2 e C3; e suas respectivas instituições: F1, F2 e F3.

As entrevistas foram transcritas e analisadas como práticas discursivas, conforme a proposta de Iñiguez e Antaki (1994). De acordo com eles, a análise de discurso não é uma técnica fixa e prescritiva, mas "um método flexível, interpretativo e, mais que nada, intelectualmente responsável" (p.58). Para nortearmos a análise, consideramos os enunciados com base em dois parâmetros: se os/as participantes representam o grupo em questão e se o discurso tem efeitos sobre a realidade, operando num nível supraindividual.

A representatividade aqui não se remete ao conceito estatístico, mas à constatação de que o/a interlocutor/a está posicionado/a e se posiciona como coordenador/a e docente da disciplina psicologia médica. Assim, ele/a fala por um coletivo, não expressando opiniões exclusivamente pessoais. Ainda em relação à representatividade e coerentes com a postura construcionista, afirmamos que nos interessa saber como as práticas discursivas engendram conhecimentos situados (Haraway, 1991). Dito de maneira mais clara, não há a busca de universalização ou generalização a respeito dos lugares que a psicologia ocupa na formação médica em nosso país, mas como ela é produzida num contexto específico. Para uma visão mais ampla do que ocorre no Brasil, consideramos fundamental que estudos semelhantes sejam feitos em outros cursos de medicina e em outras regiões do país.

Afirmamos que, neste artigo, o pesquisador está presente nos vários momentos da análise, seja pela seleção dos trechos utilizados de cada entrevista, seja pela organização desses trechos em uma narrativa. Essa postura ocorre por entendermos que a entrevista é uma prática discursiva e que cada fala está inserida no contexto de sua produção, o que implica considerar fundamental tanto a presença do/a entrevistado/a quanto a do entrevistador, das vozes que são presentificadas e dos posicionamentos que acontecem durante a entrevista.
${ }^{3}$ A pesquisa foi realizada durante a vigência do código de ética profissional do psicólogo de 1987. Com a aprovação do novo código, em 2005 (Conselho Federal de Psicologia, 2005), foi verificado que o estudo a ele também se adequava, assim como à Resolução 016/2000 do mesmo órgão (Conselho Federal de Psicologia, 2000). 
Em virtude dos limites impostos à escrita do artigo, excluímos as falas do pesquisador, dando destaque aos enunciados de seus/suas interlocutores/as. Ressaltamos, porém, que cada fala deve ser entendida como parte do processo de negociação de sentidos, o que pressupõe reconhecer que os argumentos foram produzidos nas relações interpessoais em que, a partir da fala de um (pesquisador/a ou coordenador/a) havia um direcionamento da fala do outro, construindo-se uma versão compartilhada a respeito de cada tema abordado durante as entrevistas.

A análise realizada buscou garantir o rigor, entendendo-o como a "possibilidade de explicitar os passos da análise e da interpretação de modo a propiciar o diálogo" (Spink, Lima, 1999, p.102), socializando o processo que levou às interpretações feitas. Tal procedimento se baseia em uma postura ética, pois reconhece que fazer ciência é uma prática social e dialógica, e se faz necessário garantir a visibilidade das ações utilizadas nas entrevistas e na análise dos resultados.

Dessa maneira, orientados por Iñiguez e Antaki (1994), analisamos as entrevistas, identificando e selecionando os trechos mais pertinentes para o alcance de nosso objetivo, com o cuidado de não alterar o sentido que expressavam no contexto em que foram pronunciados. Em seguida, organizamos o material em temas e os analisamos, de acordo com cada assunto abordado durante as entrevistas.

\section{Análise dos resultados}

O material colhido com os/as coordenadores/as C1, C2 e C3 foi analisado com base em três temas: a formação geral em medicina, a inserção de questões consideradas "psicológicas", e os sentidos que são atribuídos a algo "psicológico", durante a formação médica.

\section{Considerações gerais sobre a formação em medicina}

De acordo com C1 e C2, a formação em medicina engloba, essencialmente, uma formação "mais biológica" e um bom relacionamento entre médico/a e paciente.

A formação "biológica" requer: "Conhecer fisiologia e patologia" (C1). Concordando com essa visão, C2 diz que o/a aluno/a deve "receber conhecimentos suficientes que... possibilitem detectar as principais patologias, iniciar os principais tratamentos [...] isso implica em noções de propedêutica, noções de exames laboratoriais, algumas noções de terapêutica" (C2).

Já um bom relacionamento entre médico/a e paciente traz a presença do ser humano: "é lembrar que o pulmão doente pertence a uma pessoa, então essa pessoa tem que ser vista como uma pessoa que está padecendo" (C1).

Temos, então, a inclusão de questões para além do aspecto biológico do/a paciente:

[...] acho que a medicina é uma atividade que envolve o reconhecimento de determinados aspectos do que se passa com o paciente, de um ponto de vista mais biológico, mais objetivo, mais mensurável e até exato, em outros termos. Mas ela não é só isso. Ela... até pra que se atinja isso [...] é preciso haver uma interação pessoal. Não há como... ignorar ou deixar de lado isso. (C2)

C1 ressalta que não há prioridade entre os dois aspectos, enquanto que C2 lembra que a formação biológica é valorizada como um conhecimento mais científico, ou "uma ciência reconhecidamente mais clássica".

Na formação em medicina, C1 diz também considerar importante um bom relacionamento intraprofissional, "no sentido de fazer os médicos serem uma classe mais unida". Recupera, assim, a autonomia da profissão de modo que o/a médico/a deixe de se submeter às regras do mercado e às regras da medicina de grupo. Sem isso, "o médico acaba sendo substituível; você atende muito mais gente, muito mal atendido, porque... ele ganha por produção e, se ele atende poucas pessoas, ele é mandado embora" (C1).

Nos trechos acima, podemos observar alguns dos repertórios a respeito da graduação em medicina: 
formação biológica, relacionamento médico-paciente e relacionamento intraprofissional. Percebemos, assim, a tentativa de compreender cada ator social em sua multiplicidade e no contexto histórico-social em que vive.

Ainda em relação à formaçãa, C3 considera, como aspectos fundamentais, a observação e a formação: "[...] a observação é no sentido de você tomar cuidado assim de não se nortear por idéias, as idéias sem a observação. Você pode ir onde você quiser nas idéias... Na observação... você tenta derivar a tua teoria, o teu conhecimento a partir dos fatos que você observa [...]" (C3).

Acrescenta ainda que

[...] quando eu digo que o formativo nisso depende não só de você dizer para o aluno, do aluno ver isso, mas do aluno ver você fazendo isso com ele, aluno. Você trabalhar com o aluno, com o aluno não anônimo [...] Ele também tem uma história [...] $\mathrm{O}$ aspecto formativo depende também muito desse fazer, quer dizer, não depende daquilo que você diz, mas depende daquilo que você faz, quer dizer, um modelo mais identificatório [...]. (C3)

Assim também afirma C1: " [...] parto do princípio que a relação professor-aluno é a base da relação médico-paciente... quando dá aula, ele passa conhecimentos, mas passa também uma postura de como tratar, uma postura mais humanizada [...] que o aluno não veja o paciente como adversário [...]" (C1).

Sobre esse assunto, C2 declara que "medicina não é uma disciplina exata; demanda um contato do médico com o paciente. Então é fundamental que, durante a graduação, ele tenha uma formação de... senão que ele [...] não sofra uma deformação que o permita poder manter um contato satisfatório com o paciente $[\ldots . . . "(C 2)$.

A respeito do que chamou de deformação, esclarece:

[...] deformação não é algo patológico em si, mas no sentido de que o aluno do primeiro ano é diferente do aluno do sexto ano. $O$ aluno do primeiro ano está muito interessado no bem-estar do paciente. E o aluno do sexto ano, talvez até mesmo pela formação que ele passou, ele está mais focado na patologia do paciente. Isso não necessariamente faz com que o aluno do sexto ano trate mal o paciente, mas ele... o enfoque é outro. (C2)

Essa mudança é explicada por C3 da seguinte forma: "Uma coisa muito comum no exercício de medicina, no estudante de medicina e no próprio médico [...] é uma tendência a evitar a observação e a vivência dos aspectos emocionais, por exemplo". E elucida que isso ocorre, no seu entender, porque

[...] para você entrar em contato com o aspecto emocional do paciente, implica em que você possa ter esse contato com os seus aspectos emocionais. E isso, vamos dizer, nem sempre é bem-vindo... Por causa da dor, né, evitar a dor, e a própria coisa do trabalho médico, quer dizer, facilita isso, né. Existe uma exposição muito grande ao fenômeno da dor, é... do sofrimento [...]. (C3)

Durante a formação,

[...] o biológico às vezes fica muito priorizado, e os aspectos sociais e psicológicos do paciente ficam deixados de lado; têm menos importância ou então são destinados a outros profissionais. Por exemplo, hoje é comum ter psicologia hospitalar; hoje é comum ter serviço social, que supostamente ficaria encarregado de dar esse suporte pra esse tipo de visão do paciente. Novamente um fracionamento: o médico fica com o biológico, o psicólogo fica com o psicológico e o assistente social fica com o social, e sem uma integração. (C2)

A graduação médica consiste, assim, em processos de negociação entre teorias e práticas que enfatizam, em graus distintos: os aspectos biológicos, os psicológicos e os sociais. É por meio das práticas discursivas que vão se constituindo e sendo transmitidos ou refutados os enunciados e as 
diversas vozes que afirmam o que é científico (ou não). E isto pressupõe reconhecer que a ciência médica é uma coconstrução feita pelos diferentes atores sociais que dela participam.

C3 afirma que "a nossa vida é fundamentalmente mental, não existe nada fora do mental". Acrescenta que "tudo o que a gente vive, inclusive no plano físico, ele é vivido antes no plano mental". Esclarece que há uma inversão, razão pela qual ocorre uma ênfase no aspecto corporal, um privilégio nos aspectos físicos. Tal inversão ocorreria por causa de "um temor, um ódio da mente devido a esta ser impalpável, de mais difícil controle, [...] essa impalpabilidade, imprevisibilidade, acho que é alguma coisa que... fere a onipotência, um golpe na onipotência" (C3).

Ainda com relação ao "mental", complementa: "[...] a impalpabilidade da psique frustra muito aqueles que querem a coisa mais exata; a tendência de você transformar tudo em inanimado. Porque o inanimado é mais fácil de você controlar do que o animado. $\mathrm{O}$ animado, quer dizer, aquilo que tem alma, é muito mais difícil de ser observado. [...]" (C3).

As dificuldades em relação às questões psicológicas são nomeadas também por C2:

[...] Uma discussão se isso é assim mesmo, se isso é defesa, se isso é o médico que está deixando de lado o psicológico porque pra ele é difícil lidar [...] Eu acho que, às vezes, há uma necessidade de contar com o auxílio de um especialista. Mas na maioria das vezes eu acho que é uma tentativa de cindir o paciente, separar o psicológico de um lado, o físico de outro. Deixa o físico comigo e o psicológico fica pra você. (C2)

Segundo os/as coordenadores/as, várias questões contribuem para esse distanciamento, das quais uma delas decorre da própria maneira como ocorre a formação médica: " [...] a formação médica, por exemplo, implica num reconhecimento, num conhecimento científico muito bem estruturado, organizado, enfim. O aluno é treinado, ele é direcionado para aprender a identificar patologias, a identificar doenças, e não doentes [...]" (C2).

As diferenças entre as classes sociais que se fazem presentes durante a prática médica constituem uma questão que dificulta a aproximação entre profissional e paciente. No entender de C1: "existe uma tendência que diz que, se eu sou o médico, quanto mais o paciente é da minha classe social, mais eu converso e menos eu medico. Quanto mais o paciente está longe da minha classe social, menos eu converso e mais remédio eu dou".

A idade em que a maior parte dos/as alunos/as tem ao ingressar no curso de medicina também influi:

[...] O curso de medicina é um curso que coloca alunos aqui no Brasil com uma média de 18, 19 anos num contato quase que imediato com pacientes ou pessoas com patologias graves, com determinados graus, na maioria das vezes, intensos graus de sofrimento. [...] E isso traz um benefício na formação, traz uma possibilidade de o aluno saber conversar com o paciente já desde o começo; mas ao mesmo tempo tem algumas dificuldades. Logo de cara ele vê pacientes com doenças muito graves, com um sofrimento muito grande, e isso vai fazendo com que o aluno aos poucos vá se tornando mais defendido, mais protegido, mais distante [...]. (C2)

Para C2, as especializações podem propiciar o distanciamento do/a médico/a em relação ao/à paciente, visto/a, então, não como ser humano, mas como um órgão:

[...] Acho que a especialização médica também é um elemento que vem crescendo nos últimos quarenta anos, cinquenta anos... a necessidade de um médico se especializar, às vezes, já dentro do curso de graduação. Antes da residência médica ele já começa a se especializar. Isso faz com que o paciente, muitas vezes, seja visto de forma parcializada. A história clássica: não se vê o paciente, se vê o fígado do paciente porque é um especialista olhando de uma determinada ótica do que acontece com o paciente [...]. (C2) 
Para C3, em certos casos, há necessidade dessa postura de distanciamento emocional entre médico/ a e paciente: "a situação mais evidente é uma situação de emergência. Se você ficar pensando muito nos afetos, aquilo pode atrapalhar você fazer a intervenção necessária" (C3).

Percebemos, nesse subtópico, por meio da análise das vozes de C1, C2 e C3, que diferentes repertórios foram utilizados como sinônimos para nomear o mesmo fenômeno: psicológico, emocional, mental. Embora esse aspecto não tenha sido objetivo da análise realizada, vale registrar que diferentes repertórios podem expressar distintas visões de mundo, e que, por sua vez, podem contribuir para a construção de variadas versões do que é a ciência ou do que é algo considerado científico. Entendemos que isso pode explicar as similaridades e contradições expressas nas vozes de $\mathrm{C} 1, \mathrm{C} 2$ e C3, a respeito da graduação em medicina, de um ponto de vista mais geral.

\section{A inserção de questões "psicológicas" na formação médica}

Sabemos que consta, das diretrizes curriculares para os cursos de graduação em medicina (Brasil, 2001a, 2001b), a obrigatoriedade de disciplinas que abordem e desenvolvam conteúdos ligados às dimensões psicológicas, sociais e culturais do ser humano. Entretanto, cabe a cada faculdade determinar a grade de disciplinas, com os respectivos conteúdos, abordagem teórica, duração, metodologia e formas de avaliação.

Todos/as os/as coordenadores/as foram unânimes em apontar a disciplina psicologia médica como central na discussão das questões ligadas ao "psicológico" durante a formação em medicina.

A disciplina psicologia médica é ministrada durante o sexto semestre na $\mathrm{F} 1$; durante os três primeiros, na F2; e durante os dez primeiros, na F3. Segundo C1, a função da referida disciplina "é basicamente ver a relação médico-paciente, relação aluno/a-colegas de disciplina, relação professor/aaluno/a na faculdade". Esclarece que esse fato se deve ao "princípio que a relação professor-aluno é a base da relação médico-paciente; de alguma forma, os alunos tratam os pacientes da mesma forma em que eles são tratados pelo professor" (C1).

A disciplina é entendida também como "uma tentativa já tradicional [...] de procurar manter e introduzir dentro do currículo médico bases humanas de medicina, que permitam que o estudante se torne menos frio, menos duro, menos inacessível ao sofrimento do paciente" (C2).

De acordo com C2, consegue-se a inclusão mediante o aprendizado de que as relações interpessoais fazem parte de uma melhor ação médica: "a gente tenta encaminhar num certo sentido esse aspecto formativo, né, que é o sentido de formar o médico dentro de uma postura do contato humano; de ele poder estar consigo e com o outro numa postura de contato humano" (C3).

Busca-se minimamente que os/as alunos/as atentem às práticas sociais de que fazem parte: “[...] que eles saiam mais sensibilizados [...] com aspectos da relação médico-paciente e aspectos da relação médico-médico... E também, obviamente, com outros membros da equipe porque, de repente, o enfermeiro não é respeitado, a assistente social não é respeitada" (C1).

Apesar disso, C2 questiona ainda a efetividade do ensino médico:

[...] se ele sai de fato podendo ter uma compreensão mais global do que se passa com aquela pessoa, não só do ponto de vista biológico, [...] se ele vai compreender aquela pessoa de uma maneira um pouco mais... global. Tem um jargão até aí que virou até uma coisa um pouco chata de falar, mas a visão biopsicossocial do paciente é uma preocupação que se tem tido para que o aluno não perca essa visão [...]. (C2)

Esclarecendo sobre o "jargão chato de se falar", comenta que "[...] se fala tanto em biopsicossocial que a pessoa começa a banalizar o biopsicossocial. Parece o mesmo lenga-lenga de sempre: é o biopsicossocial, já sei. Então tá legal. Então vou estudar o fígado, que é o que interessa" (C2).

Segundo todos/as os/as coordenadores/as, as estratégias metodológicas utilizadas na disciplina podem variar, assim como os conteúdos abordados. Entretanto, são consideradas fundamentais as experiências coletivas e de cada um. Sobre isso, C3 afirma: "Isso é que eu queria deixar claro: não é 
um curso teórico. Isso não é dado como teoria, a gente até dá uns textos, às vezes discute, mas em forma de seminário até mais que em termos de aula, mas sempre voltado pra experiência" (C3).

Todos/as os/as interlocutores/as afirmaram que a disciplina psicologia médica é fundamental na inserção e entendimento das questões psicológicas durante o curso de medicina. O momento em que ela se insere e a sua duração variam conforme a instituição e a grade curricular. Porém, em todas elas várias vozes se tornam presentes, por meio de diferentes recursos metodológicos, se interanimando e contribuindo na produção de sentidos a respeito do "psicológico".

\section{Os sentidos de "psicológico" na formação médica}

Vários são os sentidos de "psicológico" presentes durante a formação em medicina. Abordaremos essa questão sob três perspectivas: o "psicológico" no cuidado ao/à aluno/a, o "psicológico" na prática médica, e o alcance da formação a respeito do "psicológico" nos cursos de medicina.

\section{O "psicológico" no cuidado com o/a aluno/a: dessensibilizando o sofrimento}

Percebemos uma preocupação considerável, por parte de nossos/as interlocutores/as, com os/as seus/suas alunos/as, pois consideram a psicologia médica um lugar privilegiado para a atenção e o cuidado com o sofrimento decorrente ou maximizado pelas experiências vividas durante o curso de medicina. "[...] Como é que é a vivência de estar lá com um cadáver, que experiências que isso despertou. Como é que escolheu medicina, vocação, isso no primeiro ano já é colocado, já é discutido. O contato com o hospital, o contato com os pacientes [...]" (C3).

Esse cuidado com o/a aluno/a também é relatado por C2:

[...] Enfim, uma série de relatos de experiências dos alunos que mostram que esse aluno, se não tivesse talvez a oportunidade de falar um pouco durante o aprendizado, durante uma aula, [...] ele talvez fosse julgar que... não é muito correto... se sentir mal perante um cadáver. E que isso talvez seja um indício de que ele não tem vocação pra ser médico, de que ele não tem capacidade pra seguir adiante no curso. [...] Então, não é que a gente está deixando o paciente de lado, [...] se a gente não der suporte para o que se passa com o aluno durante esses anos, [...] isso... pode não ser bom, causar um malefício para o paciente e também para o próprio profissional [...]. (C2)

O/a coordenador/a afirma que, durante as aulas, são desenvolvidas atividades para lidar com essas questões:

[...] é um espaço semanal [...] que eles têm pra poder discutir a prática que eles estão tendo, para poder discutir o envolvimento emocional que eles estão tendo com essa prática. A gente acha que se não refletir, se não discutir, se não pensar nisso, isso fica para o lado e isso esfria o aluno [...] cada vez mais deixando de considerar aspectos psicológicos, inclusive dele mesmo [...]. (C2)

C2 também considera que a atenção e o cuidado com o/a aluno/a ocupam lugar de destaque na disciplina psicologia médica:

[...] Quer dizer, basicamente o curso do primeiro ano é esse; é um curso que não ensina psicologia médica no sentido tradicional de ensinar a psicologia para os alunos. Mas busca o tempo inteiro seguir, acompanhar e oferecer uma possibilidade de que o aluno possa discutir o que ele vem paulatinamente passando durante a sua formação médica [...]. (C2) 


\section{O "psicológico" na prática: o foco na "relação"}

Neste tópico, lembramos, preliminarmente, que os problemas que ocorrem no relacionamento entre médico/a e pacientes têm sido campo fértil de estudos e publicações (Nunes, 1999; Cudizio Filho, 1996; Spink, 1994; entre outros autores).

Os/as coordenadores/as asseguram que, durante a disciplina, há uma ênfase no aspecto relacional. Sobre isto, C2 explica:

[...] a gente tenta dar no curso de medicina, não relação aluno-paciente, no primeiro ano, mas aluno-formação, o aluno na própria graduação. A relação dele, que ele vai estabelecendo com o passar do tempo que ele vai se formando, relação com a anatomia, relação com os animais de experimentação, relação dele com a entrada na faculdade, relação dele com os pacientes que ele já vai ter no segundo semestre, e assim por diante. A gente vai sempre procurando observar esse modelo mais relacional que ele vai estabelecendo. [...]. (C2)

C3 também afirma que, na F3, o curso se desenvolve por meio do estudo das relações sociais:

[...] Então o curso está focado na relação. Nesse sentido, sim, tudo é relação na vida, tanto a relação com outras pessoas quanto intrapsiquicamente também. E, no caso, a gente, quando a gente tenta trazer isso mais pra perto da relação médico-paciente, mas partindo de todas as relações. Quando você vai falar da personalidade, você está falando da relação, a estruturação da personalidade é fundada na relação.[...]. (C3)

Assim, de acordo com C2, os conteúdos da disciplina vão sendo aprendidos também de forma relacional e contextualizados nas práticas ocorridas durante a formação:

[...] Inclusive, no segundo semestre, é um módulo quase que inteiro muito voltado já para o contato dele como estudante de medicina com os pacientes. [...] E aí a gente já começa a treinar eles (sic), tanto do ponto de vista de como chegar, como se aproximar, o que é que é uma entrevista médica, o que... que é uma... dificuldades psicológicas que podem surgir de um ou de ambos os lados, não só do lado do paciente, mas do lado do estudante de medicina. E a gente segue o curso do segundo semestre inteiro fazendo isso até que, no fim do ano, eles fazem uma história, e a gente discute com cada aluno, com cada dupla que faz a história, a gente discute... aspectos psicológicos que poderiam ser reconhecidos ou que puderam ser reconhecidos durante essa atividade [...]. (C2)

O alcance da formação a respeito do "psicológico" nos cursos de Medicina

Todos/as interlocutores/as, atendendo a nossa solicitação, se pronunciaram a respeito de como entendem a formação a respeito do psicológico na faculdade em que trabalham. Assim, segundo C2:

Eu acho que ele sai sabendo que o paciente tem um psicológico. Eu acho que, às vezes, ele não sabe o que fazer... [...] Eles até reconhecem que o paciente está com um grau de sofrimento, [...] eles lidam com o sofrimento psicológico da mesma maneira como se ele tivesse tendo um sofrimento urinário, eventualmente, ou um sofrimento gástrico, ou um sofrimento neurológico qualquer. [...] Se eles reconhecem que o paciente está ansioso, eles vão chamar um psicólogo ou um psiquiatra pra manejar a ansiedade daquela pessoa, da mesma maneira que um especialista vai manejar a arritmia do paciente [...]. (C2)

De acordo com C1, a formação a respeito do psicológico é

[...] extremamente precária. É o que eu falei. [...] Até tem professores que dizem “isso é psicológico". Mas na prática param por aí, ponto. O aluno que entenda o que quiser com isso. Frequentemente o tal do psicológico é, entre aspas, aquilo que eu não consigo palpar, 
nem transmitir, nem ouvir, então é psicológico. O que fazer com isso? Ah, manda para o psiquiatra. [...]. (C1)

C3 nos apresenta outra versão sobre o provável alcance da educação que os/as professores/as propiciam:

[...] tem fases em que a gente fica se perguntando "puxa, mas será que estamos conseguindo? Como isso está repercutindo?". [...] Às vezes, a gente fica mais animado, quando a gente vê alunos que passaram pelo curso ou que estão no próprio curso; então você vê eles (sic) aproveitando; você vê transformação, você percebe isso. E outras vezes você olha e pensa "Puxa vida, será que...?" "Quanto esforço, o que será... qual o resultado de tanto esforço?". [...] Na maioria das vezes a gente, felizmente, na maior parte do tempo a gente está assim com a... vivência de que é importante, que produz efeitos. [...] Uma coisa interessante é assim: os alunos mais para o fim do curso quererem ampliar a psicologia médica [...]. (C3)

Por outro lado, e adicionando outras questões que extrapolam o ensino médico, C3 relata a inclusão das trajetórias pessoais de cada aluno/a, as quais podem dificultar a apreensão dos conteúdos abordados na(s) disciplina(s) que coordenam:

Agora, por exemplo, em cada turma, sempre tem gente que você vai encontrar que é totalmente refratário. Quer dizer, não adianta, não tem aproveitamento. [...] Mas que seriam pessoas, por exemplo, que têm condições muito pobres de entrar em contato com essas dimensões e poder usar isso na tarefa médica e no relacionamento médico-paciente [...]. (C3)

Refletindo sobre a disciplina psicologia médica, C1 observa sob outra perspectiva: "Você há de convir que é muita pretensão eu querer muita coisa, né? Só que não depende de mim a duração do curso; é coisa da grade da faculdade. Eu acho que um curso de três meses, uma manhã por semana, dado para um terceiro ano, tem um poder de fogo... não dos maiores [...]" (C1).

Assim, as alterações necessárias são vistas sob a ótica do tempo de duração: "se a disciplina durasse mais tempo, mais anos" (C1). C2, por sua vez, afirma que "a gente muda sempre todo ano. Todo ano a gente muda alguma estratégia pra sensibilizar os alunos".

Há, ainda, que apontar a importância da aproximação e integração com outras disciplinas ou áreas de conhecimento, relatada por C1: "Eu acho que a disciplina deveria ter mais ligações com outras disciplinas: o curso de psicologia, antropologia, artes em geral" (C1).

A proposta do diálogo interdisciplinar entre as Ciências Sociais e Ciências Humanas também é exposta por C2: " [...] deveria haver uma articulação um pouco maior entre as disciplinas que... que formam esse bloco, vamos chamar assim. Não só a psicologia médica, mas as Ciências Sociais junto com a Ética" (C2).

Fica nítido que alguns aspectos da formação médica têm introduzido dificuldades e contribuído para um aumento do sofrimento inerente à prática médica (lidar com doentes, com a morte, com intervenções dolorosas e invasivas etc.). Não só os pacientes têm prejuízos decorrentes desse tipo de graduação, mas também médicos e alunos de medicina. Na tentativa de minimizar esses efeitos, são oferecidos, aos estudantes, lugares onde possam partilhar suas experiências, falar de suas angústias, medos e dúvidas desencadeados durante a graduação.

Percebemos, assim, que as disciplinas ligadas à área das Ciências Humanas são consideradas relevantes durante a época em que o aluno de medicina está em formação, por serem locais considerados acolhedores e que preservam a possibilidade de expressão dos sentimentos, aspecto indissociável do ser humano. 


\section{Conclusões}

A análise das entrevistas que fizemos com professores/as-coordenadores/as da disciplina psicologia médica, em cursos de medicina na cidade de São Paulo, torna explícita a necessidade de se situar a prática médica num contexto relacional. Tenta-se, por meio da referida disciplina, incorporar uma visão mais humanística na formação que propiciam nos cursos de medicina de que fazem parte.

Percebemos que os relacionamentos entre professor/a-aluno/a, aluno/a-aluno/a, médico/a-médico/ a se tornam instrumentos de conscientização para as questões que perpassam a relação médico/apaciente. Por meio do estudo das práticas discursivas, podemos afirmar que, nas entrevistas, o "psicológico" tem prioritariamente três sentidos: em primeiro lugar, é a capacidade de comunicação entre as pessoas; a possibilidade de ambos - médicos/as e pacientes - poderem se expressar e se entender. Desse modo, a dialogia também se faz presente como algo fundamental de ser considerado na educação médica, levando-se em conta o contexto histórico e social no qual se desenrolam as práticas sociais.

O "psicológico" é ainda a capacidade de reconhecer os aspectos psicológicos do/a paciente, daqueles/as que precisam de atenção especializada (como no caso dos quadros psicóticos, depressivos etc.) e que necessitam ser encaminhados a outro/a profissional. Incluem-se, aqui, os diferentes repertórios interpretativos utilizados para nomear algo considerado psicológico e que necessita de atenção por parte do/a médico/a.

Por outro lado, as questões psicológicas englobam as formas de expressão do ser humano, muitas vezes consideradas como ameaçadoras pelos/as médicos/as, e que precisam ser identificadas e explicadas, numa tentativa de controlar e afastar os sentimentos que podem ser despertados.

Apesar de se ter afirmado que as questões relacionadas a algo "psicológico" são tratadas, sobretudo, na disciplina psicologia médica, os/as próprios/as coordenadores/as reconhecem que a educação médica não prioriza as teorias psicológicas. Porém, fica claro que o ensino de questões psicológicas se dá durante as práticas interpessoais ocorridas em sala de aula, entre os/as alunos/as e destes/as com os/as professores/as.

Para concluir, entendemos que se torna imperativo dar continência às emoções suscitadas durante a graduação em medicina, pois ela exige que se lide com o sofrimento, a dor e a morte. A disciplina psicologia médica é um lugar para o/a aluno/a expressar os sentimentos vividos, além de lhe serem propiciados acolhimento e cuidado psicológico por parte dos/as docentes.

\section{Colaboradores}

Os autores Sérgio Seiji Aragaki e Mary Jane Paris Spink participaram, igualmente, de todas as etapas de elaboração do artigo. 


\section{Referências}

BAKHTIN, M.M. Marxismo e filosofia da linguagem. São Paulo: Hucitec, 1929/1995.

BALINT, M. O médico, seu paciente e a doença. Rio de Janeiro: Atheneu, 1975.

BOLTANSKI, L. As classes sociais e o corpo. Rio de Janeiro: Graal, 1979.

BRASIL. Ministério da Saúde. Conselho Nacional de Saúde. Diretrizes e Normas Regulamentadoras de Pesquisas Envolvendo Seres Humanos. Resolução 196/96. Brasília, 1996.

Ministério da Educação e Cultura. Diretrizes curriculares para os cursos de graduação. Disponível em: <http://www.mec.gov.br>. Acesso em: 01 ago. 2001a.

Ministério da Educação e Cultura. Minuta do anteprojeto das diretrizes curriculares nacionais dos cursos de graduação em medicina. Disponível em: <http:// www.mec.gov.br>. Acesso em: 01 ago. 2001b.

CAPRARA, A.; FRANCO, A.L.S. A relação paciente-médico: para uma humanização da prática médica. Cad. Saude Publica. Rio de Janeiro, v. 15, n.3, p.647-54, 1999.

Disponível em: <http://www.scielosp.org/scielo.php?script=sci_arttext6pid=SO102$311 \times 19990003000023 \&$ Ing $=$ en \&nrm=ISO > . Acesso em: 16 jul. 2008. doi: 10.590/ so102-311X19990003000023.

CONSELHO FEDERAL DE PSICOLOGIA. Código de ética profissional do psicólogo. Resolução CFP n. 010/05. Brasília, 2005.

Dispõe sobre a realização de pesquisa em Psicologia com seres humanos. Resolução CFP n. 016/2000. Brasília, 20 dez. 2000.

15 ago. 1987.

Código de ética profissional do psicólogo. Resolução CFP n. 02/87. Brasília,

CRUZ, E.M.T.N. A formação do médico: algum as reflexões. Arq. Cienc. Saude, v.11, n.1, p.53-4, 2004.

CUDIZIO FILHO, O. Da possibilidade de dar voz ao paciente: um estudo de caso sobre a consulta homeopática. 1996. Dissertação (Mestrado em Psicologia Social) Programa de Estudos Pós-Graduados em Psicologia Social, Pontifícia Universidade Católica de São Paulo, São Paulo. 1996.

DAVIES, B.; HARRÉ, R. Positioning: the discursive production of selves. J. Theory Soc. Behav., v.20, n.1, p.44-63, 1990.

FOUCAULT, M. O nascimento da clínica. Rio de Janeiro: Forense Universitária, 1979.

GERGEN, K. The social construction movement in modern psychology. Amer. Psychol., v.40, n.3, p.266-75, 1985.

HARAWAY, D. Conocimientos situados: la cuestión científica en el feminismo y el privilegio de la perspectiva parcial. In: Ciencia, cyborgs y mujeres: la

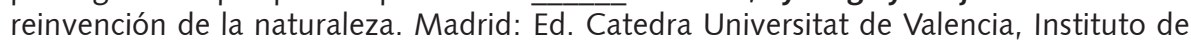
la Mujer, 1991. p.313-46.

IÑIGUEZ, L.; ANTAKI, C. El analisis del discurso em Psicología Social. Bol. Psicol., v.44, p.55-75, 1994.

JASPERS, K. Il medico nell'età della tecnica. Milano: Raffaello Cortina Editore, 1991.

MATTA, G.C.; CAMARGO JR., K.R. O processo saúde-doença como foco da Psicologia: as tradições teóricas. In: SPINK, M.J. (Org.). A psicologia em diálogo com o SUS. São Paulo: Casa do Psicólogo, 2007. p.129-40.

NUNES, E.D. Sobre a sociologia da saúde. São Paulo: Hucitec, 1999. 
PERESTRElLO, D. A medicina da pessoa. Rio de Janeiro: Atheneu, 1974.

PESSOTTI, I. A formação humanística do médico. Medicina (Ribeirão Preto), v.29, n.4, p.440-8, 1996.

POTTER, J. et al. Discourse: noun, verb or social practice. Phylosophical Psychol., v.3, n.2, p.205-17, 1990.

SCHNEIDER, P.B. Psicologia medica. Milano: Feltrinelli Editore, 1994.

SPINK, M.J. (Org.). Práticas discursivas e produção de sentidos no cotidiano: aproximações teóricas e metodológicas. São Paulo: Cortez, 1999.

Permanência e diversidade nas representações sociais da hipertensão arterial essencial. Temas Psicol., n.2, p.199-212, 1994.

SPINK, M.J.; LIMA, H. Rigor e visibilidade: a explicitação dos passos da interpretação. In: SPINK, M.J. (Org.). Práticas discursivas e produção de sentidos no cotidiano: aproximações teóricas e metodológicas. São Paulo: Cortez, 1999. p.93-122.

SPINK, M.J.; MEDRADO, B. Produção de sentidos no cotidiano: uma abordagem teórico-metodológica para análise das práticas discursivas. In: SPINK, M.J. (Org.). Práticas discursivas e produção de sentidos no cotidiano: aproximações teóricas e metodológicas. São Paulo: Cortez, 1999. p.41-62.

WERTSCH, J.V. Beyond Vygotsky: Bakhtin's contribuition. In: Voices of the mind. Cambridge, Massachusetts: Harvard University Press, 1991. p.46-66.

WETHERELL, M.; POTTER, J. El análisis del discurso y la identificación de los repertorios interpretativos. In: GORDO, A.; LINAZA, J. (Orgs.). Psicologías: discurso y poder. Madrid: Visor, 1988. p.63-78.

ARAGAKI, S.S.; SPINK, M.J.P. Los lugares de la psicología en la educación médica. Interface - Comunic., Saúde, Educ., v.13, n.28, p.85-98, jan./mar. 2009.

Este artículo plantea los lugares que la psicología ocupa en tres cursos de medicina de la ciudad de São Paulo, Brasil. Tiene como base teórica la aproximación de las prácticas discursivas en el referencial de la construcción de la psicología social. Para alcanzar tal objetivo entrevistamos a docentes responsables por la disciplina de psicología médica en los cursos referidos. El análisis del material nos ha permitido constatar que no se da prioridad en la formación a las teorías psicológicas; se las aprende durante las relaciones interpersonales que ocurren entre los alumnos y entre alumnos y profesores. Concluimos que la disciplina de psicología médica es el espacio de aprendizaje y reflexión respecto a la relación entre el futuro médico y sus pacientes, además de ser un lugar para trabajar y cuidar de las diversas experiencias suscitadas a los alumnos durante el curso de graduación.

Palabras clave: Educación médica. Psicología médica. Psicología social. Prácticas discursivas. Construcción social. 